\title{
Flaky Tail Mouse Denotes Human Atopic Dermatitis in the Steady State and by Topical Application with Dermatophagoides pteronyssinus Extract
}

\author{
Catharina Sagita Moniaga, ${ }^{*}$ Gyohei Egawa, ${ }^{\star \dagger}$ \\ Hiroshi Kawasaki, ${ }^{\ddagger}$ Mariko Hara-Chikuma, ${ }^{*}$ \\ Tetsuya Honda, ${ }^{*}$ Hideaki Tanizaki, ${ }^{*}$ \\ Saeko Nakajima, ${ }^{*}$ Atsushi Otsuka, ${ }^{*}$ \\ Hiroyuki Matsuoka, ${ }^{\S}$ Akiharu Kubo, ${ }^{\ddagger}$ \\ Jun-ichi Sakabe, ${ }^{\text {" }}$ Yoshiki Tokura, ${ }^{\pi}$ \\ Yoshiki Miyachi, ${ }^{*}$ Masayuki Amagai, ${ }^{\ddagger}$ \\ and Kenji Kabashima*† \begin{abstract}
Graduate School of Medicine, Kyoto University, Kyoto; the
Department of Dermatology, ${ }^{\ddagger}$ Faculty of Medicine, Keio University, Tokyo; the Division of Medical Zoology, Jichi Medical University, Tochigi-ken; and the Department of Dermatology, "Iniversity of Occupational and Environmental Health, Fukuoka, Japan
\end{abstract} \\ From the Department of Dermatology,* and the Center for \\ Innovation in Immunoregulative Technology and Therapeutics, ${ }^{\dagger}$
}

The barrier abnormality, a loss-of-function mutation in the gene encoding filaggrin (FLG), which is linked to the incidence of atopic dermatitis (AD), is a recently discovered but important factor in the pathogenesis of AD. Flaky tail $\left(F / g^{f t}\right)$ mice, essentially deficient in filaggrin, have been used to investigate the role of filaggrin on $\mathrm{AD}$. However, the relevancy of Flg $^{f t}$ mice to human AD needs to be determined further. In this study, we observed the clinical manifestations of $\mathrm{Flg}^{\mathrm{ft}}$ mice in the steady state and their cutaneous immune responses against external stimuli, favoring human AD. Under specific pathogen-free conditions, the majority of $\mathrm{Flg}^{\mathrm{ft}}$ mice developed clinical and histological eczematous skin lesions similar to human AD with outside-to-inside skin barrier dysfunction evaluated by newly devised methods. In addition, cutaneous hapten-induced contact hypersensitivity as a model of acquired immune response and a mite extract-induced dermatitis model physiologically relevant to a human AD were enhanced in $\mathrm{Flg}^{f t}$ mice. These results suggest that the $\mathrm{Flg}^{f t}$ mouse genotype has potential as an animal model of $\mathrm{AD}$ corresponding with filaggrin mutation in human AD. (Am J Pathol 2010, 176:2385-2393; DOI: 10.2353/ajpath.2010.090957)
Atopic dermatitis (AD), which affects at least $15 \%$ of children in developed countries, is characterized by eczematous skin lesions, dry skin, and pruritus. ${ }^{1-3}$ Although the precise pathogenic mechanism of $A D$ is as yet unknown, several accumulated lines of evidence suggest that a defective skin barrier to environmental stimuli may contribute to its pathogenesis. It has long been thought that the barrier abnormality in AD is not merely an epiphenomenon but rather is the "driver" of disease activity. ${ }^{4}$ The evidence for a primary structural abnormality of the stratum corneum in $A D$ is derived from a recently discovered link between the incidence of $A D$ and loss-of-function mutations in the gene encoding filaggrin ( $F L G$ ). Individuals carrying the FLG null allele variants tend to develop $A D .^{5-7}$

Filaggrin protein is localized in the granular layers of the epidermis. Profilaggrin, a $400-k D a$ polyprotein, is the main component of keratohyalin granules. ${ }^{8-10}$ In the differentiation of keratinocytes, profilaggrin is dephosphorylated and cleaved into 10 to 12 essentially identical $27-k D a$ filaggrin molecules, which aggregate in the keratin cytoskeleton system to form a dense protein-lipid matrix. ${ }^{10}$ This structure is thought to prevent epidermal water loss and impede the entry of external stimuli, such as allergens, toxic chemicals, and infectious organisms. Therefore, filaggrin is a key protein in the terminal differentiation of the epidermis and in skin barrier function. ${ }^{11}$

Because $A D$ is a common disease for which satisfactory therapies have not yet been established, understanding the mechanism of AD through animal models is an essential issue. ${ }^{1,12}$ Flaky tail $\left(\right.$ Flg $\left.^{\text {ft }}\right)$ mice, first introduced in 1958, are spontaneously mutated mice with

Supported in part by the Ministry of Education, Culture, Sports, Science and Technology of Japan and the Ministry of Health, Labor, and Welfare of Japan.

Accepted for publication January 11, 2010

Supplemental material for this article can be found on http://ajp. amjpathol.org.

Address reprint requests to Dr. Kenji Kabashima, M.D., Ph.D., Department of Dermatology and Center for Innovation in Immunoregulative Technology and Therapeutics, Kyoto University Graduate School of Medicine, 54 Shogoin-Kawara, Kyoto 606-8507, Japan. E-mail: kaba@kuhp.kyoto-u.ac.jp. 
abnormally small ears, tail constriction, and a flaky appearance of the tail skin, which is most evident between 5 and 14 days of age. ${ }^{13}$ Mice of the Flgtt genotype express an abnormal profilaggrin polypeptide that does not form normal keratohyalin $\mathrm{F}$ granules and is not proteolytically processed to filaggrin. Therefore, filaggrin is absent from the cornified layers in the epidermis of the Flg ${ }^{\text {th }}$ mouse. ${ }^{14-16}$

Recently, it has been revealed that the gene responsible for the characteristic phenotype of $F / g^{t t}$ mice is a nonsense mutation of 1-bp deletion analogous to a common human FLG mutation. ${ }^{15}$ These mice developed eczematous skin lesions after age 28 weeks under specific pathogen-free (SPF) conditions ${ }^{17}$ and enhanced penetration of tracer perfusion determined by ultrastructural visualization, ${ }^{16}$ and were predisposed to develop an allergen-specific immune response after epicutaneous sensitization with the foreign allergen ovalbumin (OVA). ${ }^{15,17}$ On the other hand, general immunity through intraperitoneal sensitization with OVA was comparable between $\mathrm{Flg}^{f t}$ mice and control mice. ${ }^{15,17}$

Despite these recent advances, there still remain several issues with $\mathrm{Flg}^{\text {ft }}$ mice to be addressed. For example, serial close observation of clinical manifestations in reference to human $A D$ will be informative. It is of value to evaluate the responses to external stimuli relevant to human $\mathrm{AD}$, such as mite extracts, instead of OVA that has been used previously. A comparative study on the skinmediated contact hypersensitivity (CHS) response and non-skin-mediated delayed-type hypersensitivity response is important to evaluate the impact of barrier dysfunction on immune responses in vivo. In addition, although it has now been determined that the barrier dysfunction is a key element in the establishment of $A D$, there is no established method to evaluate the outside-to-inside barrier function quantitatively.

In this study, we found that Flg ${ }^{f t}$ mice showed spontaneous dermatitis with skin lesions mimicking human $A D$ in a steady state under SPF conditions: serial occurrence of manifestations as scaling, erythema, pruritus, and erosion followed by edema in this order. We also successfully evaluated outside-to-inside barrier dysfunction in $\mathrm{Flg}^{f t}$ mice quantitatively using a newly developed method. In addition, we determined that the Th1/Tc1-mediated immune response was enhanced by immunization through skin but not through non-skin immunization. Last, we induced severe AD-like skin lesions in Flg ${ }^{\text {ft }}$ mice by application of mites as a physiologically relevant antigen for human $A D$, which will be an applicable animal model of AD.

\section{Materials and Methods}

\section{Mice}

C57BL/6NCrSlc (B6) mice were purchased from SLC (Shizuoka, Japan). Flaky tail (STOCK a/a ma ft/ma ft/J; $\mathrm{Flg}^{\text {tt }}$ mice) mice have double-homozygous filaggrin (Flg) and matted (ma) mutations. ${ }^{13,14}$ We used B6 mice as a control of $\mathrm{Flg}{ }^{f t}$ mice because $\mathrm{Flg} g^{f t}$ mice were described to be outcrossed onto B6 mice at The Jackson Laboratory $\left(\right.$ Bar Harbor, ME) ${ }^{13,14}$ (of note, although the strain was crossed with $\mathrm{B} 6$, it is not a $\mathrm{B} 6$ congenic strain but rather a hybrid stock that is probably semi-inbred). Female mice were used in all experiments unless otherwise stated; they were maintained on a 12-hour light/dark cycle at a temperature of $24^{\circ} \mathrm{C}$ and at a humidity of $50+10 \%$ under SPF conditions at Kyoto University Graduate School of Medicine. Routine colony surveillance and diagnostic workup verified that mice were free of Ectromelia virus, lymphocytic choriomeningitis virus, mouse hepatitis virus, Sendai virus, Mycoplasma pulmonis, cilia-associated respiratory bacillus, Citrobacter rodentium [Escherichia coli O115a,c:K(B)], Clostridium piliforme (Tyzzer's organism), Corynebacterium kutscheri, Helicobacter hepaticus, Pasteurella pneumotropica, Salmonella spp., parasites, intestinal protozoans, Enterobius, and ectoparasites. All experimental procedures were approved by the Institutional Animal Care and Use Committee of Kyoto University Graduate School of Medicine.

\section{Clinical Observation and Histology}

The clinical severity of skin lesions was scored according to the macroscopic diagnostic criteria that were used for the NC/Nga mouse. ${ }^{18}$ In brief, the total clinical score for skin lesions was designated as the sum of individual scores, graded as 0 (none), 1 (mild), 2 (moderate), and 3 (severe), for the symptoms of pruritus, erythema, edema, erosion, and scaling. Pruritus was observed clinically for more than 2 minutes.

For the histological portion of the study, the dorsal skin of mice was stained with H\&E. Toluidine blue staining was used to detect mast cells, and the number of mast cells was calculated as the average from five different fields of each sample $\times 40$ magnification).

\section{Flow Cytometric Analysis and Quantitative $R T-P C R$}

Cells from the skin-draining axillary and inguinal lymph nodes (LNs) and from the spleen were analyzed with flow cytometry. Fluorescent-labeled anti-CD4 and anti-CD8 antibodies were obtained from eBioscience (San Diego, $\mathrm{CA}$ ) and used to stain cells. The total number of cells per organ and the number of cells in each subset were calculated through flow cytometry using the FACSCanto II system (Becton Dickinson, San Diego, CA). Quantitative RT-PCR was performed as described previously, using the housekeeping gene glyceraldehyde-3-phosphate dehydrogenase $(G A P D H)$ as a control. ${ }^{19}$

\section{Total and Mite-Specific Serum IgE}

Total serum IgE levels were measured with a mouse IgE ELISA Kit (Bethyl Laboratories, Montgomery, TX) according to the manufacturer's protocols. For the measurement of mite-specific IgE levels, the same type of mouse IgE ELISA Kit was used with slightly modifications. Specifi- 
cally, plates were coated and incubated with $10 \mu \mathrm{g} / \mathrm{ml}$ Dermatophagoides pteronyssinus (Dp) (Biostir, Kobe, Japan) diluted with coating buffer for 60 minutes. After a blocking period of 30 minutes, $100 \mu \mathrm{l}$ of $5 \times$ diluted serum was added into each well and incubated for 2 hours. Anti-mouse IgE-horseradish peroxidase conjugate $(1: 15,000 ; 100 \mu \mathrm{L})$ was used to conjugate the antigen-antibody complex for 60 minutes at room temperature; from this point on the ELISA Kit was used according to the manufacturer's protocol. Absorbance was measured at $450 \mathrm{~nm}$. The difference between the sample absorbance and the mean of negative control absorbance was taken as the result.

\section{Skin Barrier Function}

The dorsal regions of the skin were shaved in all mice before measurement. To evaluate inside-to-outside barrier function, transepidermal water loss (TEWL) was measured with a Tewameter Vapo Scan (Asahi Biomed, Tokyo, Japan) at $24^{\circ} \mathrm{C}$ and $46 \%$ relative humidity.

Outside-to-inside barrier function was assessed by means of fluorescein isothiocyanate isomer I (FITC) (Sigma-Aldrich, St. Louis, MO). The shaved dorsal skin of mice was treated with $100 \mu \mathrm{l}$ of $1 \%$ FITC diluted in acetone and dibutyl phthalate (1:4); 3 hours later, this area was tape-stripped (Scotch tape, 3M, St. Paul, MN) nine times to remove the stratum corneum containing the remnant of FITC. The painted area $(1.2 \mathrm{~cm} \times 1.2 \mathrm{~cm})$ was removed, and FITC concentration was measured. Each skin sample was soaked in PBS at $60^{\circ} \mathrm{C}$ for 10 seconds, after which the dermis and epidermis were separated. The epidermis was soaked in $500 \mu$ l of PBS, homogenized, and spun down at $2200 \times g$. The supernatant was collected, and fluorescence was measured at an excitation wavelength of $535 \mathrm{~nm}$ and an emission wavelength of $460 \mathrm{~nm}$ using an Arvo SX 1420 counter (Wallac, PerkinElmer, Waltham, MA). The fluorescence value was compared with a standard curve using FITC serial dilutions.

For the evaluation of fluorescence intensities of FITC penetrated into the epidermis, a $1 \times 1 \mathrm{~cm}$ skin sample was taken after tape stripping, and a 10- $\mu \mathrm{m}$ Tissue-Tek (Sakura Finetek, Tokyo, Japan)-embedded section was analyzed using a BZ-9000 Biorevo digital microscope (Keyence, Osaka, Japan) at the same time exposure.

An in situ dye permeability assay with toluidine blue was performed using embryos at 18 days (littermates). Unfixed, untreated embryos were dehydrated by a 1-minute incubation in an ascending series of methanol $(25,50,74$, and $100 \%)$ and rehydrated with the descending same methanol series, washed in PBS, and stained with $0.01 \%$ toluidine blue.

\section{Scratching Behavior}

Scratching behavior was measured in detail using the Sclaba Real system (Noveltec, Kobe, Japan). Mice were put into the machine 20 minutes before measurement to allow them to adapt to the new environment. Ointment was then applied, and the number and duration of scratching sessions were counted according to the manufacturer's protocol for 15 minutes. ${ }^{20}$

\section{Dermatitis Models}

For the assessment of irritant contact dermatitis, $20 \mu \mathrm{l}$ of 0.2 $\mathrm{mg} / \mathrm{ml}$ phorbol myristate acetate (PMA) (Sigma-Aldrich) was applied to both sides of the ears. Ear thickness change was measured at $1,3,12$, and 24 hours as well as 5 days after application.

To induce a CHS response, $25 \mu$ of $0.5 \%$ 1-fluoro-2.4dinitrobenzene (DNFB) (Nacalai Tesque, Kyoto, Japan) was painted on the shaved abdomens of mice for sensitization. Five days later, the ears were challenged with $20 \mu \mathrm{l}$ of $0.2 \%$ DNFB, and ear thickness change was measured at 24 and 48 hours after application. Nonsensitized mice were used as a control. A delayed-type hypersensitivity response model was established using OVA (Sigma-Aldrich). Mice were sensitized with $200 \mu \mathrm{l}$ of $0.5 \mathrm{mg} / \mathrm{ml}$ of OVA in complete Freund's adjuvant (Difco Laboratories, Detroit, MI) intraperitoneally and challenged 5 days later with an injection of $20 \mu \mathrm{l}$ of $1 \mathrm{mg} / \mathrm{ml}$ of OVA in incomplete Freund's adjuvant (Difco Laboratories) into the hind footpads. Footpad thickness was measured before and 24 hours after challenge. Nonsensitized mice were used as a control. Footpad swelling was calculated by (footpad thickness change of sensitized mice) - (footpad thickness change of nonsensitized mice). To induce murine AD-like skin lesions, $40 \mathrm{mg}$ of $0.5 \% \mathrm{Dp}$ in white petrolatum was topically applied to the ears and upper back twice a week for 8 weeks. Petrolatum without Dp was used as a control. One gram of Dp body product (Biostir) contained $1.78 \mathrm{mg}$ of total protein with $2.47 \mu \mathrm{g}$ of $\mathrm{Dp}$ protein (Der p1). Ear thickness and clinical scores were measured every week. Mite-specific IgE levels, TEWL, and histological appearance of eczematous skin were observed 12 hours after the final application.

\section{Statistical Analysis}

Data were analyzed using an unpaired two-tailed $t$-test. $P<0.05$ was considered to be significant.

\section{Results}

\section{Spontaneous Dermatitis of Flg ${ }^{\mathrm{ft}}$ Mice in the Steady State under SPF Conditions}

As described previously, ${ }^{14,15}$ the expression of the filaggrin monomer was barely detectable by Western blotting in the dorsal skin of $\mathrm{Flg}^{\text {ft }}$ mice compared with that of B6 mice (data not shown). Here, we investigated the clinical manifestations seen in the skin of $F / g^{f t}$ mice raised in a steady state under SPF conditions and found that $\mathrm{Flg}^{\text {th }}$ mice developed spontaneous dermatitis (Figure 1A). The clinical severities of skin lesions, including pruritic activity, erythema, edema, erosion, and scaling, were scored. The total clinical scores of $\mathrm{Flg}^{\text {tt }}$ mice increased with age 
A
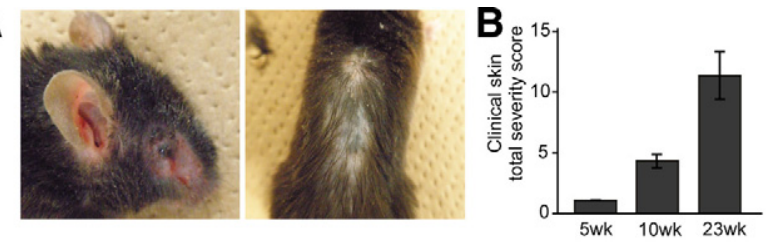

C

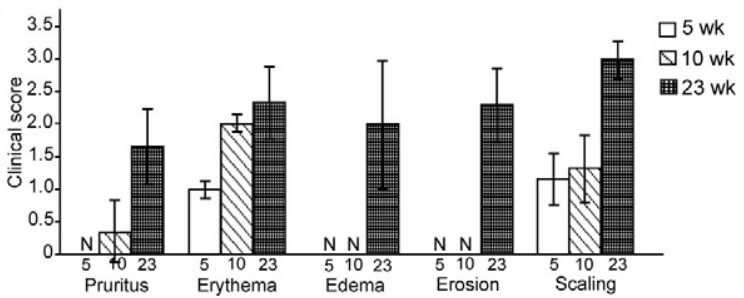

D

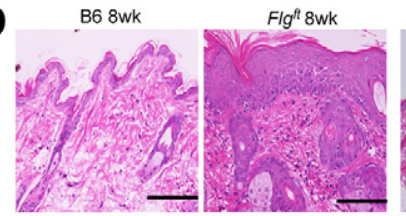

B6 18wk

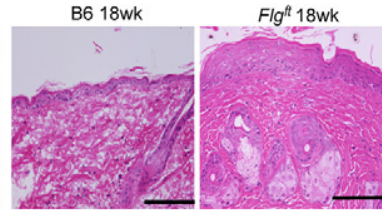

$\mathbf{E}$
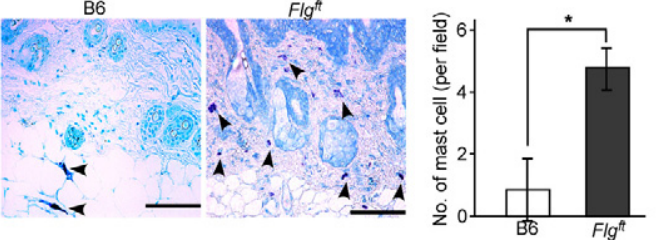

Figure 1. Spontaneous dermatitis in $\mathrm{Flg}^{f t}$ mice in SPF. A: Clinical photographs of 20 -week-old $F l g{ }^{f t}$ mice. Total clinical severity scores (B) for each particular item $(\mathbf{C})$ in 5-, 10- and 23-week-old $F / g^{f t}$ mice. N, none. D: H\&E-stained sections in 8 - and 18-week-old mice. Scale bar $=100 \mu \mathrm{m}$. E: Toluidine blue staining of the skin from 8-week-old B6 and Flg $^{f t}$ mice and the numbers of mast cells (arrowheads) per field are shown. ${ }^{*} P<0.05$.

(Figure 1B). The first manifestations to appear when mice were young were erythema and fine scaling; pruritic activity, erosion, and edema followed later (Figure 1C). In contrast, no cutaneous manifestation was observed in either B6 mice, studied as a control, or heterozygous mice intercrossed with Flgt and B6 mice kept under SPF conditions throughout the experimental period (data not shown). In addition, there was no apparent difference in terms of clinical manifestations between the genders of Flg ${ }^{f t}$ mice throughout the period (data not shown).

Histological examination of skin from $\mathrm{Flg}^{\text {ft }}$ mice revealed epidermal acanthosis, increased lymphocyte infiltration, and dense fibrous bundles in the dermis in both younger (8-week-old) and older (18-week-old) Flg ${ }^{\text {ft }}$ mice; none of these were observed in B6 mice (Figure 1D). In addition, toluidine blue staining to detect mast cells showed an increased number of mast cells, especially degranulated mast cells in the upper dermis, in Flg ${ }^{\text {ft }}$ mice (Figure 1E). No mouse or human mite bodies were detected in the sections. These data support the diagnosis of spontaneous clinical dermatitis in $\mathrm{Flg}^{\text {ft }}$ mice in the steady state under SPF conditions.

\section{Defect of Skin Barrier Function in Flg ${ }^{\text {ft }}$ Mice}

Because barrier dysfunction is a common characteristic of $A D,{ }^{4-7,21}$ we measured TEWL, an established indicator
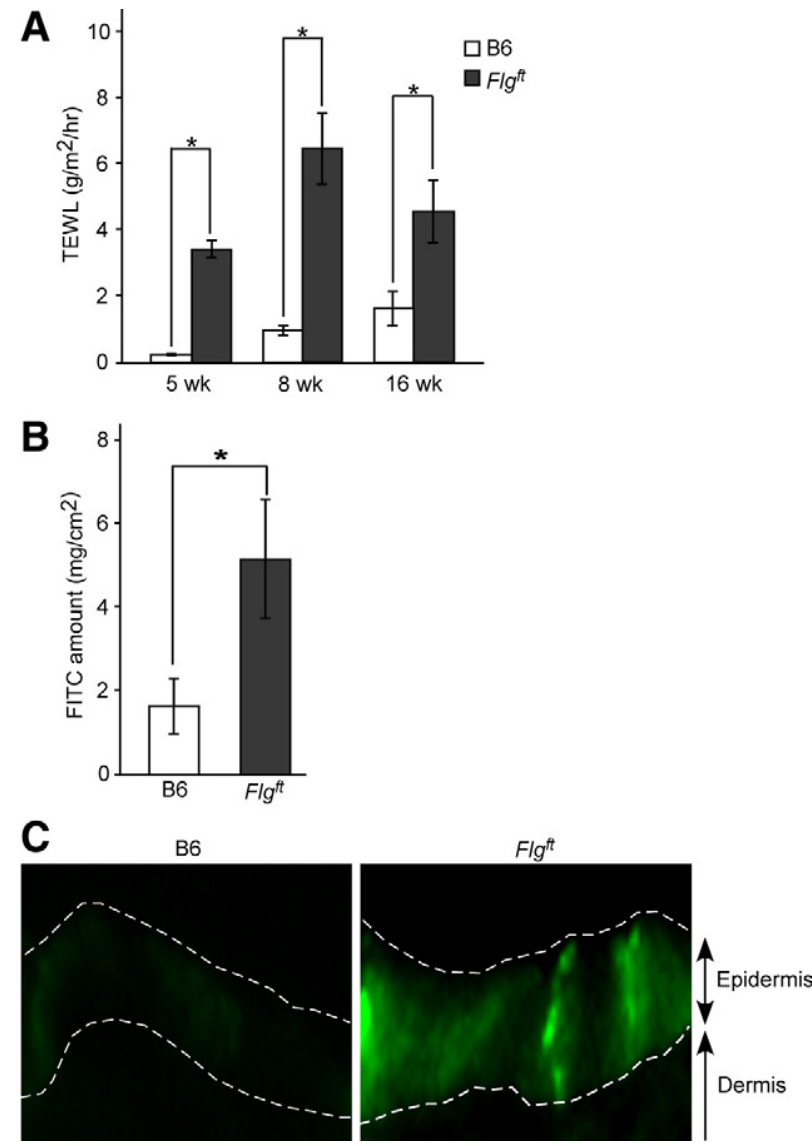

Figure 2. Skin barrier dysfunction in $\mathrm{Flg}^{f t}$ mice. A: TEWL through dorsal skin of 5-, 8-, and 16-week-old B6 and Flg ${ }^{f t}$ mice. B: Amount of FITC in the skin of B 6 and $F / g{ }^{f t}$ mice after topical application. C: Fluorescence intensities of FITC of the skin after topical application. Dashed white lines indicate the border between the epidermis and the dermis, and the top of the epidermis. ${ }^{*} P<0.05$.

of barrier function. ${ }^{21}$ TEWL was significantly higher in Flg ${ }^{f t}$ mice than in B6 mice from an early age (4 weeks) to an older age (16 weeks) (Figure 2A). Because TEWL is only a measure of water transportation through the skin from the inside to the outside of the body, another experimental method was necessary to evaluate outside-to-inside barrier function from the perspective of invasion of external stimuli. To address this issue, we measured FITC penetration through the skin from the outside. FITC solution was applied to the shaved dorsal skin of 8-week-old female mice; 3 hours later, the epidermis was separated and homogenized so that the FITC content could be measured with a fluorometer. The epidermis of $\mathrm{Flg}^{\mathrm{ft}}$ mice contained a higher amount of FITC than that of B6 mice (Figure 2B). Neither group had FITC in the dermis after this procedure, however (data not shown). In addition, observation of fluorescence intensities in the epidermis of both mice showed stronger fluorescence in $\mathrm{Flg}^{\mathrm{ft}}$ mice (Figure 2C). To further analyze the skin permeability, we examined the mouse embryos by toluidine blue solution and showed that the Flg ft embryo was entirely dye-permeable compared with the control littermate (Supplemental Figure S1, see http://ajp.amjpathol.org). These data strongly indicate a defect in the skin barrier of $\mathrm{Flg}^{\mathrm{ft}}$ 


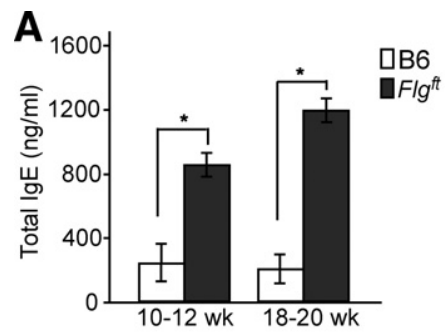

B Skin-draining LN
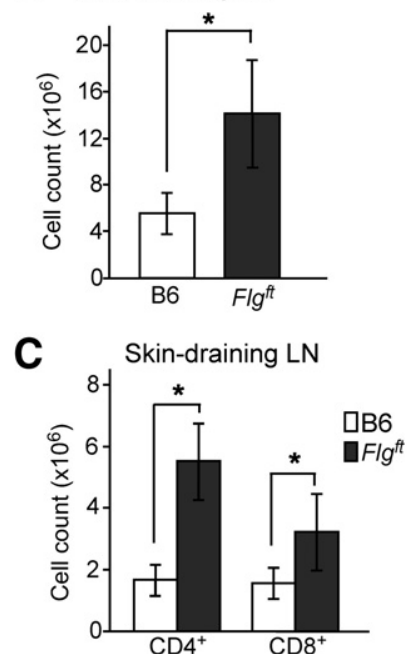

Figure 3. The immune status of $F l g . f t$ mice in a steady state. A: Total serum IgE levels of B6 and Flg ${ }^{f t}$ mice as measured by enzyme-linked immunosorbent assay. $\mathbf{B}$ and $\mathbf{C}$ : Numbers of total cells $(\mathbf{B}), \mathrm{CD}^{+}$cells, and CD8 ${ }^{+}$cells in the skin-draining $\mathrm{LN}$ and spleen $(\mathbf{C}) .{ }^{*} P<0.05$.

mice, both from inside to outside and from outside to inside.

\section{Immune Status in the Steady State}

To further elucidate the immune status of $\mathrm{Flg}^{\text {ft }}$ mice in the steady state under SPF conditions, we measured the levels of total serum IgE, because increased severity of $\mathrm{AD}$ is known to be correlated with elevated serum IgE levels. ${ }^{22} \mathrm{IgE}$ levels were significantly higher in Flg ${ }^{\mathrm{ft}}$ mice than in age-matched B6 mice in the steady state under SPF conditions (Figure 3A). To investigate this matter in greater detail, single cell suspensions from the skindraining inguinal and axillary LNs and from the spleen were analyzed. The total mononuclear cell number of the LNs was significantly higher in Flg $\mathrm{gt}^{\mathrm{ft}}$ mice than in B6 mice, but that of the spleen was comparable (Figure 3B). In addition, $\mathrm{Flg} \mathrm{g}^{\text {ft }}$ mice exhibited significantly higher numbers of $\mathrm{CD}_{4}^{+}$and $\mathrm{CD}^{+}$cells in the skin-draining LNs, but not in the spleen (Figure 3C). Thus, an enhanced immune reaction seems to be induced in $\mathrm{Flg}^{\mathrm{ft}}$ mice by the condition of their skin.

To further analyze the immune condition of the skin, we measured the Th1 (interferon- $\gamma[\mathrm{IFN}-\gamma]$ ), Th2 (interleukin [IL]-4 and IL-13), and Th17 (IL-17) cytokine mRNA levels of dorsal skin of 9-week-old mice in the steady state. The mRNA expression levels of IFN- $\gamma$, IL-4, and IL-13 were similar between $\mathrm{Flg}^{\mathrm{ft}}$ and $\mathrm{B} 6$ mice, but there was an
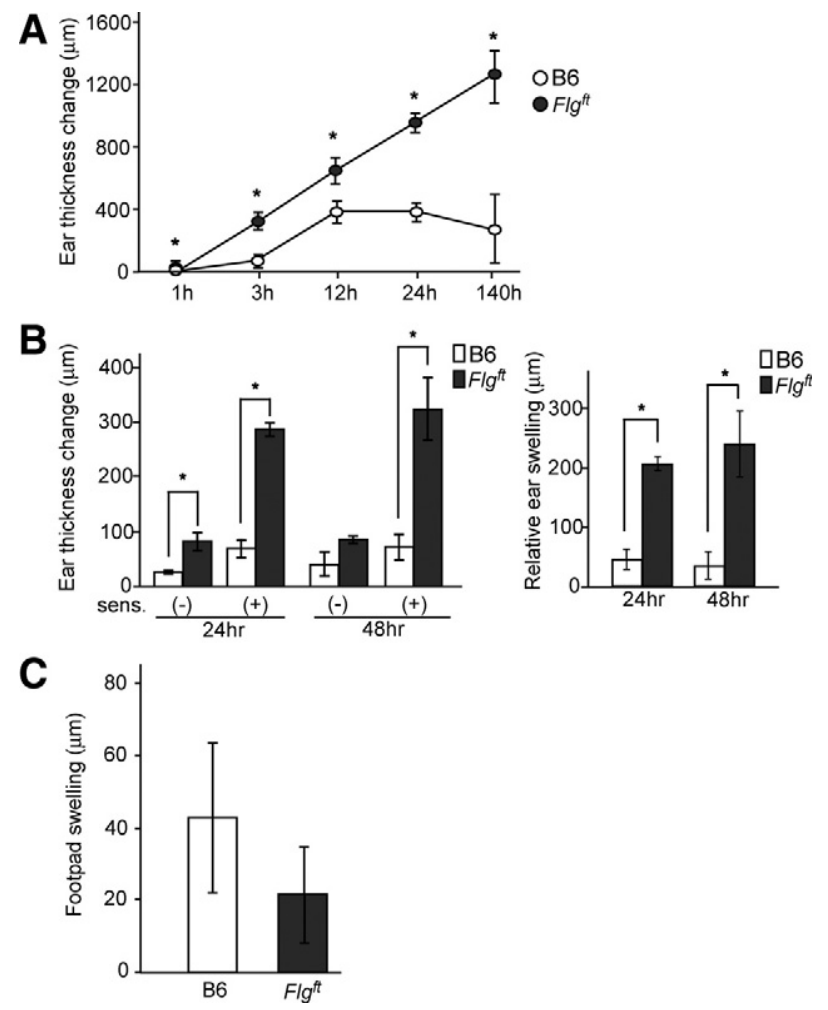

Figure 4. Enhanced cutaneous immune responses in $F l{ }^{f t}$ mice. $\mathbf{A}$ and $\mathbf{B}$ : Ear thickness change in $\mathrm{B} 6$ and $F / g^{f t}$ mice after topical application of PMA as a model of irritant contact dermatitis (A), after DNFB challenge on the ears with or without sensitization (B, left panel) and the relative ear swelling (B right panel) as a model of CHS. C: Delayed-type hypersensitivity response. $\mathrm{B} 6$ and $\mathrm{Flg}^{f t}$ mice were intraperitoneally sensitized with OVA, and challenged through subcutaneous injection to the footpad. Twenty-four hours later, footpad swelling change was measured. ${ }^{*} P<0.05$.

enhancement in the IL-17 mRNA expression (data not shown) as reported previously. ${ }^{17}$

\section{Enhanced Dermatitis in Flg ${ }^{\mathrm{ft}}$ Mice under External Stimuli}

To characterize the likelihood of various cutaneous immune responses, mice were exposed to various external stimuli. First, we studied the irritant contact dermatitis response to PMA as an irritant agent. When we applied PMA to the ears of $\mathrm{B} 6$ and $\mathrm{Flg}^{\mathrm{ft}}$ mice, $\mathrm{Flg} \mathrm{g}^{\mathrm{tt}}$ mice exhibited an enhanced ear swelling response compared with agematched B6 mice throughout the experimental period (Figure 4A). Next, we measured the CHS response to DNFB. DNFB was applied to the abdominal skin for sensitization; 5 days later, the ears were challenged with the same hapten. The ear thickness change was more prominent in Flg ${ }^{\text {tt }}$ mice than in B6 mice (Figure 4B, left panel). On the other hand, the ear thickness change of mice without sensitization was higher for $\mathrm{Flg}^{\text {ft }}$ mice than B6 mice, suggesting that irritation contact dermatitis was enhanced in $\mathrm{Flg}^{\mathrm{ft}}$ mice as expected. To avoid the involvement of this irritation in $\mathrm{CHS}$, we next analyzed the relative ear swelling by subtracting the ear thickness change without sensitization from the ear thickness change with sensitization. The relative ear swelling was more exten- 
A
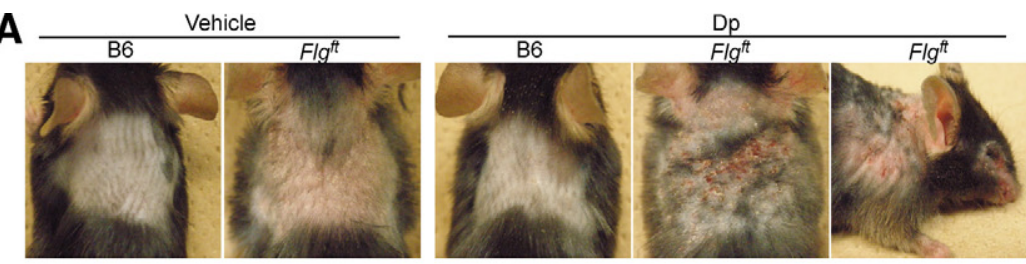

B

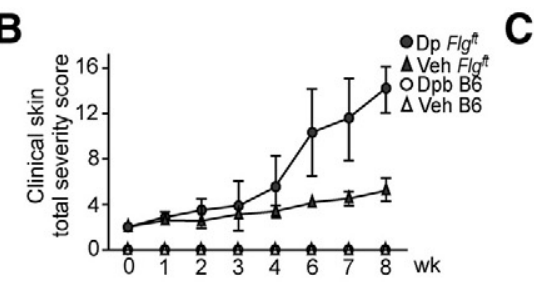

D

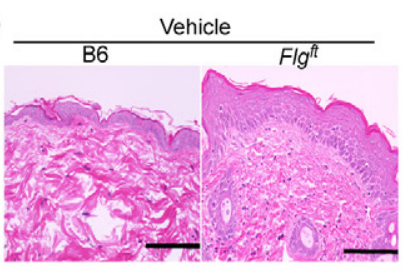

B6

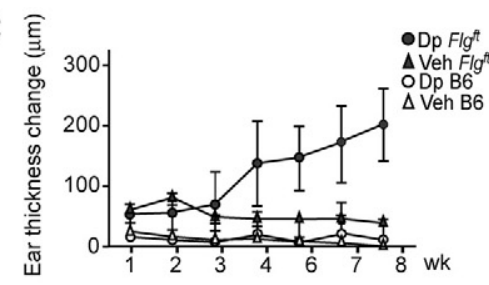

E

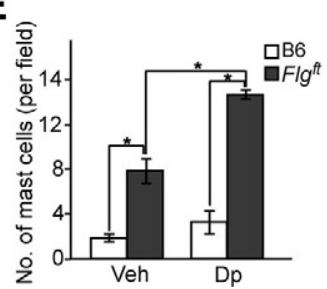

$\mathbf{F}$

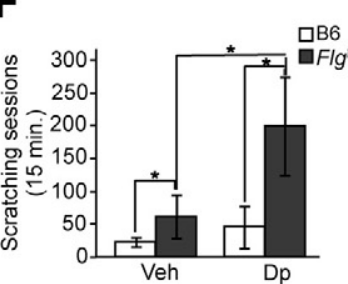

Figure 5. Mite (Dp)-induced dermatitis model. B6 and Flg ${ }^{f t}$ mice were topically treated with ointment with (Dp) or without (vehicle/Veh) Dp. A-C: Clinical photographs after the last application of Dp (A), clinical skin severity scores $(\mathbf{B})$, and changes in ear thickness $(\mathbf{C})$ at each indicated time point after application. $\mathbf{D}$ and $\mathbf{E}$ : Histological appearance of the skin (D) and the numbers of mast cells (E) after the last application. Scale bars = $100 \mu \mathrm{m}$. F: Scratching behavior: the number of scratching sessions (left) and the total duration of scratching (right) over 15 minutes after the last application. G: TEWL after the last application. H: Serum mite-specific IgE levels. ${ }^{*} P<0.05$. sive in Flg $g^{f t}$ mice than in B6 mice (Figure 4B, right panel). We then measured the relative amount of mRNA for IFN- $\gamma$, as a representative Th1 cytokine, to GAPDH as an endogenous control. The relative amount of IFN- $\gamma$ was higher in the ears of $\mathrm{Flg}^{\mathrm{ft}}$ mice than in those of B6 mice 12 hours after the challenge $(0.27 \pm 0.13$ versus $0.019 \pm$ $0.013, n=3)$. To further assess the immune responses of Flg ${ }^{f t}$ mice, we elicited a delayed-type hypersensitivity response through nonepicutaneous sensitization and challenge. Mice were immunized intraperitoneally with OVA and challenged with a subcutaneous injection of OVA into the footpad. In contrast to the CHS response induced via the skin, the resulting footpad swelling in Flgt mice was lower rather than higher than that in B6 mice (Figure 4C). We also examined the production of mRNA levels of the spleen 3 days after intraperitoneal OVA injection, and it showed a similar level of IFN- $\gamma$ between Flg ${ }^{f t}$ mice and B6 mice (relative mRNA amount to GAPDH: $0.011 \pm 0.005$ versus $0.016 \pm 0.006, n=5$ ). Thus, Th1/Tc1 immune responses were enhanced in Flg ${ }^{\text {ft }}$ mice only when the stimuli operated via the skin, suggesting that the enhanced immune responses seen in Flg ${ }^{f t}$ mice depend on skin barrier dysfunction.

It has been reported that $F / g^{f t}$ mice show an enhanced immune response to OVA. ${ }^{15,17}$ Their reaction to clinically relevant allergens such as mites has not been evaluated, however. It has also been reported that BALB/C or NC/ Nga mice develop an allergic cutaneous immune response to mite antigens when they are applied to the skin after vigorous barrier disruption by means of tape-strip- ping or SDS treatment. ${ }^{23,24}$ Accordingly, we sought to determine whether skin lesions could be induced in Flg ${ }^{\text {ft }}$ mice through the application of Dp ointment without any skin barrier disruption procedures to evaluate the physiological significance of filaggrin.

The application of Dp ointment to shaved backs and ears induced no cutaneous manifestation in B6 mice throughout the experimental period (Figure 5, A and B), but the same treatment induced dermatitis in $\mathrm{Flg}^{\mathrm{ft}}$ mice, especially on the ears, face, and dorsal skin. Petrolatum alone, used instead of Dp ointment as a control, induced no skin manifestation (Figure $5, A-C$ ). The clinical severity of Dp-induced dermatitis was scored; after 16 applications of Dp ointment over 8 weeks, Flg ${ }^{f t}$ mice had developed a very severe skin condition in contrast with the control groups. Consistently, ear swelling in response to Dp ointment was most prominent in Flg ${ }^{f t}$ mice (Figure 5C). Histological examination of H\&E-stained sections of involved Flgt skin after 16 applications showed acanthosis, elongation of rete ridges, and dense lymphocyte and neutrophil infiltration in the dermis (Figure 5D), accompanied by an increased number of mast cells in the dermis (Figure 5E). We also measured the scratching behavior of Flg ${ }^{\text {tt }}$ mice treated with Dp using the Sclaba Real system. The number of scratching sessions and the total duration of scratching were significantly higher in Flg ${ }^{f t}$ mice than in B6 mice, even among those mice that had not been treated with Dp ointment (Figure 5F); treatment of Flgt mice with Dp ointment raised the number of scratching sessions and the total duration of scratching even higher. 
We further evaluated barrier function by measuring TEWL in Dp-treated and untreated mice of each genotype; TEWL was higher in untreated $\mathrm{Flg}^{\mathrm{ft}}$ mice than in B6 mice, and Dp treatment of $\mathrm{Flg}^{\mathrm{ft}}$ mice raised TEWL even higher (Figure 5G). Finally, we examined mite-specific serum IgE levels after the last application and found that $\mathrm{Flg}^{\mathrm{ft}}$ mice had higher levels of Dp-specific IgE than B6 mice had (Figure $5 \mathrm{H}$ ). Thus, the treatment of $F / g^{f t}$ mice with $\mathrm{Dp}$ ointment, even without prior barrier disruption, remarkably enhanced both the clinical manifestations and the laboratory findings that correspond to indicators of human AD.

\section{Discussion}

Here, we demonstrated that Flgt mice exhibit spontaneous dermatitis with lymphadenopathy, elevated IgE levels, and skin barrier disruption in a steady state under SPF conditions. These outcomes are compatible with the features of human $A D$, which include chronic eczema, pruritus, and dry skin with elevated TEWL and serum IgE levels. ${ }^{1-4,25,26}$ In addition, Flg ${ }^{\text {ft }}$ mice exhibit enhanced susceptibility to irritant contact dermatitis, CHS, and miteinduced dermatitis compared with B6 mice; these characteristics are also reminiscent of human AD. These results suggest that the barrier defect in this strain of mice leads to spontaneous dermatitis and enhances cutaneous immune responses and inflammation.

Since the first introduction of $\mathrm{Flg}^{\mathrm{ft}}$ mice in $1972,{ }^{13}$ there have been only a few reports of these mice. The first report demonstrated that $\mathrm{Flg}^{\text {ft }}$ mice without the ma mutation showed flaky skin as early as postnatal day 2 but became normal in appearance by 3 to 4 weeks of age without spontaneous dermatitis except for their slightly smaller ears. ${ }^{13}$ Later, the lack of filaggrin in the epidermis was proposed in the commercially available strain of $\mathrm{Flg}^{\text {ft }}$ mice used in this study, which has both Flg and ma mutations, as a model of ichthyosis vulgaris, and therefore the cutaneous inflammatory conditions from the perspective of $A D$ was not discussed. ${ }^{14}$ There have been three recent studies using $\mathrm{Flg}^{\text {ft }}$ mice as a model of filaggrin deficiency: Fallon et al ${ }^{15}$ used $\mathrm{Flg}^{\mathrm{ft}}$ mice from which the ma mutation had been eliminated with four additional backcrosses to B6 mice, and others used the commercially available $\mathrm{Flg}^{\text {ft }}$ mice. ${ }^{16,17}$ The first report showed only a histological abnormality without clinical manifestations, ${ }^{15}$ the second report demonstrated spontaneous eczematous skin lesions after 28 weeks of age, ${ }^{17}$ and the third report did not indicate any spontaneous dermatitis in $\mathrm{Flg}^{\text {ft }}$ mice. ${ }^{16}$ In our experiment, we observed a spontaneous dermatitis as early as 5 weeks of age with mild erythema and fine scales. These symptoms gradually exacerbated, accompanied by scratching, erosion, and edema, respectively, and became prominent at the age of 23 weeks. The discrepancies among these results seem to be related to the presence or absence of the ma mutation and/or variation in the genetic backgrounds of the different strains used and to environmental factors. It has been reported that Japan has higher morbidity for $A D$ than other countries, ${ }^{27,28}$ possibly attributable to environmental factors such as pollen.

It has been reported that TEWL, an indicator of insideto-outside barrier function, is high in both $A D$ patients with the $F L G$ mutation ${ }^{29}$ and $F / g^{f t}$ mice. ${ }^{15}$ In consideration of the immunological defense by the skin, however, it is more important to assess outside-to-inside barrier function rather than inside-to-outside barrier function. In fact, outside-to-inside barrier dysfunction has recently been proposed as the most important aspect in the pathogenesis of AD. ${ }^{9,26}$ Scharschmidt et al $^{16}$ reported increased bidirectional paracellular permeability of water-soluble xenobiotes by ultrastructural visualization in $\mathrm{Flg}^{\text {ft }}$ mice, suggesting a defect of the outside-to-inside barrier. However, the quantitative measurement of this parameter has not been addressed. Here, we propose a new method for evaluating outside-to-inside barrier function quantitatively by measuring the penetrance of FITC through the skin. This method has a parallel correlation with the qualitative measurement of FITC penetrated in epidermis and an established method for skin permeability assay, the in situ dye staining method. Therefore, by using this new method, we were able to detect outside-to-inside barrier dysfunction in $\mathrm{Flg} g^{\text {tt }}$ mice quantitatively.

The skin abnormality associated with $A D$ is well known to be a predisposing factor to sensitive $\operatorname{skin}^{30,31}$ and allergic contact dermatitis, ${ }^{32,33}$ but patients with $A D$ produce a tuberculin response similar to that of healthy control subjects. ${ }^{34,35}$ In humans, sensitive skin is defined as reduced tolerance to cutaneous stimulation, with symptoms ranging from visible signs of irritation to subjective neurosensory discomfort. ${ }^{30,31}$ The question of whether human $A D$ patients are more prone to allergic contact dermatitis than nonatopic individuals is still controversial. ${ }^{33}$ To address this question, we evaluated skin responsiveness to PMA as an irritant and found that irritant contact dermatitis was enhanced in $\mathrm{Flg}^{f t}$ mice. In addition, $\mathrm{Flg}^{\mathrm{ft}}$ mice showed an increased skin-sensitized CHS reaction, a form of classic Th1- and Tc1-mediated delayed-type hypersensitivity to haptens, emphasized by increased IFN- $\gamma$ production. In contrast, when mice were sensitized intraperitoneally, no difference was observed between $\mathrm{Flg}^{f t}$ and $\mathrm{B} 6$ mice in vivo or in vitro. This finding is consistent with the observation that humans with and without $A D$ respond comparably to tuberculin tests ${ }^{34,35}$ and suggests that skin barrier function regulates cutaneous immune conditions, which hints at a possible mechanism involved in human AD.

Clinical studies have provided evidence that a house dust mite allergen plays a causative or exacerbating role in human $A D^{36}$ and that a strong correlation exists between patients with FLG null alleles and house dust mitespecific IgE. ${ }^{37}$ AD-like skin lesions can be induced by repeated topical application of a mite allergen in NC/Nga mice but not in BALB/c mice. ${ }^{23}$ In the present study, we induced skin lesions that were clinically and histologically similar to $A D$, along with increased TEWL, increased scratch behavior, and increased levels of mite-specific $\mathrm{IgE}$, in $\mathrm{Flg}^{\text {ft }}$ mice through the application of Dp. Dp is a common aeroallergen that is frequently involved in induction of human AD. It has protease activities, spe- 
cifically from Der p1, Der p3, and Der p9, which may activate protease-activated receptor-2 in human keratinocytes. ${ }^{38,39} \mathrm{~A}$ recent report has shown that activation of protease-activated receptor-2 through Dp application significantly delays barrier recovery rate in barrier function-perturbed skin or compromised skin. ${ }^{39}$ Therefore, Dp may play a dual role in the onset of $A D$, both as an allergen and proteolytic signal and as a perturbation factor of the barrier function, leading to the persistence of eczematous skin lesions in AD. ${ }^{39,40}$

To address the issue of variable genetic background, we observed immune responses in mice of other genotypes, such as BALB/c and $\mathrm{C} 3 \mathrm{H}$, as controls, but both of these lines exhibited much less severe $\mathrm{CHS}$ responses compared with those in Flgt mice (data not shown), suggesting that the enhanced immune responses seen in $\mathrm{Flg}^{\text {tt }}$ mice were not solely due to their genetic background. The effect of the ma mutation in relation to the $f t$ mutation in commercially available $\mathrm{Flgt}$ mice in the development of $\mathrm{AD}$-like skin lesions needs to be clarified in future studies. Furthermore, our study showed that heterozygous mice intercrossed with $\mathrm{Flg}^{\mathrm{ft}}$ mice and B6 mice did not develop spontaneous dermatitis. In this way they are unlike human $A D$ patients, most of whom are heterozygous for the FLG mutation. Not only human studies but also additional mouse studies are required to clarify these relationships.

In this study, we have shown that $\mathrm{Flg}^{\mathrm{ft}}$ mice exhibit spontaneous dermatitis resembling human $A D$, enhanced irritation dermatitis and a contact hypersensitivity response, and mite-induced AD-like skin lesions, which provide hints for possible mechanisms in the human disease. These results suggest that $\mathrm{Flg}^{f t}$ mice have the potential to serve as an animal model of human $A D$ and further accentuate the important role of filaggrin in skin barrier function in the pathogenesis of $A D$.

\section{References}

1. Jin H, He R, Oyoshi M, Geha RS: Animal models of atopic dermatitis. J Invest Dermatol 2009, 129:31-40

2. Wollenberg A, Bieber T: Atopic dermatitis: from the genes to skin lesions. Allergy 2000, 55:205-213

3. Novak N, Bieber T, Leung DY: Immune mechanism leading to atopic dermatitis. J Allergy Clin Immunol 2003, 112:S128-S139

4. Elias PM, Hatano Y, Williams ML: Basis for the barrier abnormality in atopic dermatitis: outside-inside-outside pathogenic mechanism. J Allergy Clin Immunol 2008, 121:1337-1343

5. Palmer CN, Irvine AD, Terron-Kwiatkowski A, Zhao Y, Liao H, Lee SP, Goudie DR, Sandilands A, Campbell LE, Smith FJ, O'Regan GM, Watson RM, Cecil JE, Bale SJ, Compton JG, DiGiovanna JJ, Fleckman P, Lewis-Jones S, Arseculeratne G, Sergeant A, Munro CS, El Houate B, McElreavey K, Halkjaer LB, Bisgaard H, Mukhopadhyay S, McLean $\mathrm{WH}$ : Common loss-of function variants of the epidermal barrier protein filaggrin are a major predisposing factor for atopic dermatitis. Nat Genet 2006, 38:441-446

6. Nomura T, Sandilands A, Akiyama M, Liao H, Evans AT, Sakai K, Ota M, Sugiura H, Yamamoto K, Sato H, Palmer CN, Smith FJ, McLean WH, Shimizu H: Unique mutations in the filaggrin gene in Japanese patients with ichthyosis vulgaris and atopic dermatitis. J Allergy Clin Immunol 2007, 119:434-440

7. Morar N, Cookson WO, Harper JI, Moffat MF: Filaggrin mutations in children with severe atopic dermatitis. J Invest Dermatol 2007, 127:1667-1672
8. Dale BA: Filaggrin, the matrix protein of keratin. Am J Dermatopathol 1985, 7:65-68

9. Listwan P, Rothnagel JA: Keratin bundling proteins. Methods Cell Biol 2004, 78:817-827

10. Candi E, Schmidt R, Melino G: The cornified envelope: a model of cell death in the skin. Nat Rev Mol Cell Biol 2005, 6:328-340

11. Gan SQ, McBride OW, Idler WW, Markova N, Steinert RM: Organization, structure, and polymorphisms of the human profilaggrin gene. Biochemistry 1990, 29:9432-9440

12. Shiohara T, Hayakawa J, Mizukawa $Y$ : Animal models for atopic dermatitis: are they relevant to human disease? J Dermatol Sci 2004, 36:1-9

13. Lane P: Two new mutations in linkage group XVI of the house mouse. J Hered 1972, 63:135-140

14. Presland RB, Boggess D, Lewis SP, Hull C, Fleckman P, Sundberg JP: Loss of normal profilaggrin and filaggrin in flaky tail (ft/ft) mice: an animal model for the filaggrin-deficient skin disease ichthyosis vulgaris. J Invest Dermatol 2000, 115:1072-1081

15. Fallon PG, Sasaki T, Sandilands A, Campbell LE, Saunders SP, Mangan NE, Callanan JJ, Kawasaki H, Shiohama A, Kubo A, Sundberg JP, Presland RB, Fleckman P, Shimizu N, Kudoh J, Irvine $A D$, Amagai M, McLean WH: A homozygous frameshift mutation in the mouse Flg gene facilitates enhanced percutaneous allergen priming. Nat Genet 2009, 41:602-608

16. Scharschmidt TC, Man MQ, Hatano $Y$, Crumrine D, Gunathilake R, Sundberg JP, Silva KA, Mauro TM, Hupe M, Cho S, Wu Y, Celli A, Schmuth M, Feingold KR, Elias PM: Filaggrin deficiency confers a paracellular barrier abnormality that reduces inflammatory thresholds to irritants and haptens. J Allergy Clin Immunol 2009, 124:496-506, 506.e1-e6

17. Oyoshi MK, Murphy GF, Geha RS: Filaggrin-deficient mice exhibit Th17-dominated skin inflammation and permissiveness to epicutaneous sensitization with protein antigen. J Allergy Clin Immunol 2009, 124:475-493, 493.e1

18. Leung DY, Hirsch RL, Schneider L, Moody C, Takaoka R, Li SH, Meyerson LA, Mariam SG, Goldstein G, Hanifin JM: Thymopentin therapy reduces the clinical severity of atopic dermatitis. J Allergy Clin Immunol 1990, 85:927-933

19. Mori T, Kabashima K, Yoshiki R, Sugita K, Shiraishi N, Onoue A, Kuroda E, Kobayashi M, Yamashita U, Tokura Y: Cutaneous hypersensitivities to hapten are controlled by IFN- $\gamma$-upregulated keratinocyte Th1 chemokines and IFN- $\gamma$-downregulated Langerhans cell Th2 chemokines. J Invest Dermatol 2008, 128:1719-1727

20. Orito K, Chida Y, Fujisawa C, Arkwright PD, Matsuda H: A new analytical system for quantification scratching behavior in mice. $\mathrm{Br} \mathrm{J}$ Dermatol 2004, 150:33-38

21. Gupta J, Grube E, Ericksen MB, Stevenson MD, Lucky AW, Sheth AP Assa'ad AH, Khurana Hershey GK: Intrinsically defective skin barrier function in children with atopic dermatitis correlates with disease severity. J Allergy Clin Immunol 2008, 121:725-730

22. Novak $\mathrm{N}$ : New insights into the mechanism and management of allergic diseases: atopic dermatitis. Allergy 2009, 64:265-275

23. Kang JS, Lee K, Han SB, Ahn JM, Lee H, Han MH, Yoon YD, Yoon WK, Park SK, Kim HM: Induction of atopic eczema/dermatitis syndrome-like skin lesions by repeated topical application of a crude extract of Dermatophagoides pteronyssinus in NC/Nga mice. Int Immunopharmacol 2006, 6:1616-1622

24. Yamamoto M, Haruna T, Yasui K, Takahashi H, Iduhara M, Takaki S, Deguchi M, Arimura A: A novel atopic dermatitis model induced by topical application with Dermatophagoides farinae extract in NC/Nga mice. Allergol Int 2007, 56:139-148

25. Matsumoto M, Ra C, Kawamoto K, Sato H, Itakura A, Sawada J, Ushio $\mathrm{H}$, Suto H, Mitsuishi K, Hikasa Y, Matsuda H: IgE hyperproduction through enhanced tyrosine phosphorylation of Janus kinase 3 in NC/Nga mice, a model for human atopic dermatitis. J Immunol 1999, 162:1056-1063

26. Cooper D, Hales J, Camp R: IgE-dependent activation of T cells by allergen in atopic dermatitis: pathophysiologic relevance. J Invest Dermatol 2004, 123:1086-1091

27. The International Study of Asthma and Allergies in Childhood (ISAAC) Steering Committee: Worldwide variation in prevalence of symptoms of asthma, allergic rhinoconjunctivitis, and atopic eczema: ISAAC. Lancet 1998, 351:1225-1232

28. Williams H, Robertson C, Stewart A, Ait-Khaled N, Anabwani G 
Anderson R, Asher I, Beasley R, Björkstèn B, Burr M, Clayton T, Crane J, Ellwood P, Keil U, Lai C, Mallol J, Martinez F, Mitchell E, Montefort S, Pearce N, Shah J, Sibbald B, Strachan D, von Mutius E, Weiland S: Worldwide variations in the prevalence of symptoms of atopic eczema in the international study of asthma and allergies in childhood. J Allergy Clin Immunol 1999, 103:125-138

29. Nemoto-Hasebe I, Akiyama M, Nomura T, Sandilands A, McLean WHI, Shimizu H: Clinical severity correlates with impaired barrier in filaggrin-related eczema. J Invest Dermatol 2009, 129:682-689

30. Willis CM, Shaw S, De Lacharrière O, Baverel M, Reiche L, Jourdain R, Bastien P, Wilkinson JD: Sensitive skin: an epidemiological study. Br J Dermatol 2001, 145:258-263

31. Farage MA, Katsarou A, Maibach HI: Sensory, clinical and physiological factors in sensitive skin: a review. Contact Dermatitis 2006, 55:1-14

32. Clayton TH, Wilkinson SM, Rawcliffe C, Pollock B, Clark SM: Allergic contact dermatitis in children: should pattern of dermatitis determine referral? A retrospective study of 500 children tested between 1995 and 2004 in one UK centre. Br J Dermatol 2006, 154:114-117

33. Mailhol C, Lauwers-Cances V, Rance F, Paul C, Giordano-Labadie F: Prevalence and risk factors for allergic contact dermatitis to topical treatment in atopic dermatitis: a study in 641 children. Allergy 2009, 64:801-806

34. Yilmaz M, Bingöl G, Altintas D, Kendirli SG: Correlation between atopic diseases and tuberculin responses. Allergy 2000, 55:664-667

35. Grüber C, Kulig M, Bergmann R, Guggenmoos-Holzmann I, Wahn U,
MAS-90 Study Group: Delayed hypersensitivity to tuberculin, total immunoglobulin $\mathrm{E}$, specific sensitization, and atopic manifestation in longitudinally followed early Bacille Calmette-Guerin-vaccinated and nonvaccinated children. Pediatrics 2001, 107:e36

36. Kimura M, Tsuruta S, Yoshida T: Correlation of house dust mite-specific lymphocyte proliferation with IL-5 production, eosinophilia, and the severity of symptoms in infants with atopic dermatitis. J Allergy Clin Immunol 1998, 101:85-89

37. Henderson J, Northstone K, Lee SP, Liao H, Zhao Y, Pembrey M, Mukhopadhyay S, Smith GD, Palmer CN, McLean WH, Irvine AD: The burden of disease associated with filaggrin mutations: a populationbased, longitudinal birth cohort study. J Allergy Clin Immunol 2008, 121:872-877

38. Vasilopoulos Y, Cork MJ, Teare D, Marinou I, Ward SJ, Duff GW, Tazi-Ahnini R: A nonsynonymous substitution of cystatin A, a cysteine protease inhibitor of house dust mite protease, leads to decreased mRNA stability and shows a significant association with atopic dermatitis. Allergy 2007, 62:514-519

39. Jeong SK, Kim HJ, Youm JK, Ahn SK, Choi EH, Sohn MH, Kim KE, Hong JH, Shin DM, Lee SH: Mite and cockroach allergens activate protease-activated receptor 2 and delay epidermal permeability barrier recovery. J Invest Dermatol 2008, 128:1930-1939

40. Roelandt T, Heughebaert C, Hachem JP: Proteolytically active allergens cause barrier breakdown. J Invest Dermatol 2008, 128:18781880 